\title{
Editorial \\ Business and Human Rights Scholarship: Past Trends and Future Directions
}

\section{INTRODUCTION}

When the Business and Human Rights Journal (BHRJ) was launched in 2016, we, the journal editors, embarked on a mission to make it 'an authoritative forum for scholars and practitioners to exchange cutting-edge ideas about the complex and evolving relationship of human rights with business'. ${ }^{1}$ At the three-year mark, we are proud of the journal's role in helping to define the field and promoting dialogue on many topical business and human rights (BHR) issues. $B H R J$ reaches a wide audience of both legal and non-legal BHR scholars and professionals. In 2018, the journal achieved 58,006 abstract views (34,083 in 2017) and 24,182 full text views (20,250 in 2017) through the Cambridge University Press online platform.

Looking at the ten most downloaded papers both for 2018 and overall, roughly two-thirds of those articles were written by legal scholars. This reflects almost exactly the ratio of legal to non-legal articles we have published so far. Thus, while legal scholars are still predominant in the discussion on the publication side, non-legal articles find a substantial audience as well, suggesting that BHRJ should be an equally attractive platform to publish BHR research both from legal and non-legal perspectives. This being said, many pieces authored by legal scholars take a broader approach to BHR, reaching beyond the bounds of law. Nonetheless, it is evident that there is still much to do in terms of fostering the BHR discourse beyond legal disciplines. BHRJ can and wants to play a key role in this endeavour.

Fostering a conversation between academic and non-academic exponents of the field is another goal of $B H R J$. In this vein, the top twenty downloads in 2018 and overall contain 25-30 per cent Developments in the Field (DiF) pieces. This may reflect the desire of our audience to keep abreast of key innovations and developments in the policy and practical spaces of this rapidly evolving field.

Readership of our published papers is strong. All of the top ten papers received more than 1,000 downloads so far. Four of them received more than 1,000 downloads in 2018 alone (with a fifth one achieving 998 downloads). In addition, the journal has attracted robust social media impact and visibility, which is reflected in strong Altmetric scores of many of our articles. This indicates that the articles published in BHRJ are frequently shared and commented on in social media, suggesting that the journal is contributing to conversations outside of traditional scholarly platforms, e.g., through Twitter.

Even as we celebrate and share these achievements with our readers, we also seek to examine the directions in which scholars need to push in order to more fully achieve our mission. To do so, we reached out to our exceptional Editorial Board and DiF Panel to inquire

1 Surya Deva, Anita Ramasastry, Michael Santoro and Florian Wettstein, 'Editorial' (2016) 1:1 Business and Human Rights Journal 1. 
about their views on where the biggest gaps remain in research in the BHR field. Based on their input, we have identified several areas we believe to be most in need of further exploration. This is not to suggest that our list of themes is exhaustive. Rather, it is a reflection of our collective judgement of where we have come in the BHR field and where we see it (or we would like to see it) going in the future. As Larry Backer astutely notes, we should continue to endeavour 'to curate trends rather than to serve as museum-like guardians of past sensibilities and "truths" which are now receding, being replaced by new orders and new realities'.

Despite the tremendous explosion of scholarship in the BHR field, current research has generally concentrated on certain themes. The 'nuts and bolts' of the United Nations Guiding Principles on Business and Human Rights (UNGPs), and the limits of the UNGPs, are two such themes. However, as BHR starts to mature as a distinct field, we believe that BHR scholars in the future should move beyond the UNGPs and pay greater attention to a wider range of research strands, some of which are outlined below. Even more critical is for us to give greater visibility to scholars from the Global South, welcoming their perspectives on what may be perceived as an agenda driven by scholars, policymakers and corporations from the Global North.

\section{Overarching Approaches to BHR ScholarshiP}

\section{A. Empirical Scholarship}

The BHR field has brought out strong conceptual and normative scholarship in recent years, but engaged relatively scarcely in empirical analysis so far. Thus, an 'empirical testing' of normative claims in the BHR field is one strand whose exploration we would welcome. As Denis G Arnold notes, 'the field needs rigorous empirical scholarship to test various hypotheses regarding business and human rights performance-in particular, to test hypotheses related to firm compliance with the UN framework'. Practical implications of claims as to what ought to be the nature and scope of the human rights responsibilities of businesses or the outcome efficacy of the process of human rights due diligence should be tested empirically. Similarly, the extent to which national action plans (NAPs) to implement the UNGPs have resulted in promoting business respect for human rights, to mention another example, warrants empirical investigation. Such findings could inform the evolution or revision of future NAPs to implement the UNGPs.

The current empirical testing in the BHR field is predominantly found in policy reports and civil society investigations. While such reports and investigations are critical for the field, they often remain anecdotal and lack systematic scholarly rigour as a consequence. $B H R J$ has taken the lead and already published several innovative empirical papers, which will shape and impact our understanding of how companies approach human rights. ${ }^{2}$ More such empirical investigation is needed in order to create a more holistic picture of the state of play in the BHR field.

\footnotetext{
2 Robert McCorquodale, Lise Smit, Stuart Neely and Robin Brooks, 'Human Rights Due Diligence in Law and Practice: Good Practices and Challenges for Business Enterprises' (2017) 2:2 Business and Human Rights Journal 195; Louise J Obara, “'What Does This Mean?”: How UK Companies Make Sense of Human Rights' (2017) 2:2 Business and Human Rights Journal 249; Samentha Goethals, 'Exploring Migrant Employees' "Rights-Talk" in the British Hospitality Sector' (2019) 4:2 Business and Human Rights Journal 287.
} 


\section{B. Interlinkages}

BHR 'interlinkages' and overlaps with other issues and fields on the periphery is another research strand for which we would encourage further exploration. Political democracy, tax avoidance, climate change, artificial intelligence, the Belt and Road Initiative, privatization of public services, trade and investment, migration, the role of religion, and human rights responsibilities of civil society organizations are some examples of issues with strong connections to BHR, but where other disciplines may appear predominant in the scholarly literature. Applying a BHR lens to these subjects may bring a fresh perspective to important global challenges.

Two developments related to climate change can be taken to illustrate how these interlinkages might unfold in the future. The first is the drafting of the Principles on Climate Obligations of Enterprises by a group of experts, ${ }^{3}$ and the second consists of the judicial as well as non-judicial claims against corporations for contributing to climate change. ${ }^{4}$ The latter are particularly telling, not least because they raise complex questions about causation, attribution, responsibility and extraterritoriality. Robert McCorquodale points to Indonesian cross-border pollution as a useful case for this discussion-a subject on which $B H R J$ has published a piece in the DiF section and thus set the stage for further scholarly research. ${ }^{5}$ Sara Seck cites the work of John Knox-particularly the Framework Principles on Human Rights and the Environment ${ }^{6}$ as another good starting point. As she summarizes, 'Knox explicitly identifies the need for further research and scholarly inquiry to clarify "the responsibilities of businesses in relation to human rights and the environment.",

There is much potential in exploring such issues at the periphery of BHR. This being said, if the BHR discourse starts capturing all such potential interlinkages, that would raise legitimate questions about the boundaries of our field. If the domain of BHR covers almost all governance issues, what value does it add? As the BHR field grows and expands, the scholarly exploration of such definitional questions about the contours and limits of the field's reach as well as of its very identity should gain more importance. $B H R J$ strikes us as a most suitable platform for negotiating the identity and charting the future directions of the BHR field.

\footnotetext{
3 Expert Group on Climate Obligations of Enterprises, Principles on Climate Obligations of Enterprises (The Hague, Netherlands: Eleven International Publishing, 2018).

4 See Business and Human Rights Resource Centre, 'Turning Up the Heat: Corporate Legal Accountability for Climate Change' (2018), https://www.business-humanrights.org/sites/default/files/CLA_AB_2018_Full.pdf (accessed 12 June 2018); Dutch Ministry of Foreign Affairs, 'Final Statement Dutch NCP Specific Instance, 4 NGOs Versus ING Bank' (19 April 2019), https://www.oecdguidelines.nl/latest/news/2019/04/19/final-statement-dutch-ncp-specificinstance-4-ngos-versus-ing-bank (accessed 28 May 2019). See also the Commission on Human Rights of the Philippines, 'National Inquiry on Climate Change', https://chr.gov.ph/nicc-2/ (accessed 29 May 2019).

5 Mahdev Mohan, 'A Domestic Solution for Transboundary Harm: Singapore's Haze Pollution Law' (2017) 2:2 Business and Human Rights Journal 325.

6 Human Rights Council, 'Report of the Special Rapporteur on the Issue of Human Rights Obligations Relating to the Enjoyment of a Safe, Clean, Healthy, and Sustainable Environment: Framework Principles on Human Rights and the Environment', A/HRC/37/59 (24 January 2018).

7 Ibid, para 18.
} 


\section{Structural BHR Concerns}

Future BHR scholarship should also focus on what may be termed 'structural' issues. Instead of trying to only promote business respect for human rights under the existing structures, this research strand might challenge the very ideologies, legal and policy frameworks and institutional structures, which facilitate the abuse of human rights by business actors in the first place and enable them to evade liability. For example, is it realistic and even possible to expect businesses to respect all human rights under conditions of shareholder primacy and profit maximisation, or does it require a paradigm change at the outset? As Peter Muchlinski puts it, there is a need for scholarship to explore whether we can 'further human rights compliance in a business culture wedded to ideologies of neoliberal profit maximisation and to the worldviews of business culture currently taught in management schools'. Similarly, at the state and policy level, how much pressure does the World Bank's annual Ease of Doing Business ranking $^{8}$ or the recommendations of international institutions to reform policies concerning trade, employment and social protection ${ }^{9}$ put on states to ignore human rights or environmental considerations?

Growing economic inequality ${ }^{10}$ is another structural issue that requires more than a superficial fix. Businesses have a close connection with economic inequalities: corporate operations, policies and practices not only contribute to the birth of inequalities but also exploit such inequalities, for example, when they move factories and operations in their supply chains to cut costs or avoid changes in regulations. Yet, the BHR discourse so far has either remained silent to such stark inequalities and entrenched poverty ${ }^{11}$ or treated these as a given. In either case, these structural issues have been viewed largely as beyond critical scholarly investigation from a BHR perspective. It seems evident that the current levels of economic inequalities cannot be addressed by merely expecting businesses to respect human rights voluntarily. Instead, taking such structural conditions into critical account will require bold, paradigm-shifting research. BHRJ is again keen to play a leading role in driving such innovative scholarship.

\section{Rights, Rightsholders and Corporate Accountability}

More 'rights-centric' and 'rightsholders-centric' research might be one of the most pressing needs from a larger BHR angle as well as for BHRJ more specifically. Do

\footnotetext{
8 The ranking methodology does not include any element of business respect for human rights. While data are collected regarding some labour rights issues (i.e., those related to job quality such as the availability of maternity leave, paid sick leave and the equal treatment of men and women at the workplace), these are not used to rank economies. World Bank, 'Labor Market Regulation Methodology', https://www.doingbusiness.org/content/dam/doingBusiness/ media/Methodology/Supporting-Papers/DB-Methodology-Regulation-of-Labor.pdf (accessed August 28, 2019).

9 See Paul Cammack, 'Socio-Economic Rights in the Contemporary World Market: China, India and the "Gang of Four"' in Surya Deva (ed.), Socio-Economic Rights in Emerging Free Markets: Comparative Insights from India and China (London, UK: Routledge, 2017) 21.

10 'In the period between 2006 and 2015, ordinary workers saw their incomes rise by an average of just $2 \%$ a year, while billionaire wealth rose by nearly $13 \%$ a year -almost six times faster. .. $82 \%$ of all growth in global wealth in the last year went to the top $1 \%$, while the bottom half of humanity saw no increase at all'. Oxfam, Reward Work, Not Wealth (Oxford, UK: Oxfam, 2018) 10.

11 See Uwe Gneiting, 'Inequality, Business and Human Rights: The New Frontier?', https://www.businesshumanrights.org/en/inequality-business-and-human-rights-the-new-frontier (accessed 13 June 2018).
} 
'human rights' in BHR actually mean rights, entailing (legally) enforceable duties against businesses? How do such rights become manifest for affected individuals and communities on the ground? For example, are corporate consultations with communities that face displacement by development projects merely a symbolic tick box exercise for companies to get the projects approved or do such consultations provide a real voice to the communities and truly protect their human rights? It is worth investigating incidences of projects that were disapproved or modified substantially after consultation with communities as part of human rights impact assessments. Similarly, persistent lack of mechanisms to provide effective remedies to the victims of business-related human rights abuses as well as to hold corporations accountable should continue to challenge BHR scholars interested in rights and rightsholders.

Addressing such gaps, Sarah Joseph calls for more scholarship focusing on enforcement and 'actual crystallisation of hard law obligations' in both domestic and international law. Her observation that 'BHR has possibly become too much of a "safe space" for business, and there is not enough focus on penalties and consequences of getting it wrong' is momentous and noteworthy. It should give us pause for critical (self) reflection: how can we, as a scholarly community, make sure that those whose rights are affected negatively by business activities remain at the core of our scholarly concerns? Furthermore, we hope there could be some appetite for exploring differentiated and disproportionate adverse impacts of business activities on different groups of rightsholders such as children, women, people with disabilities, indigenous peoples, migrant workers and people with different sexual orientations. ${ }^{12}$ An informed understanding of the specific contexts and situations of various disadvantaged or vulnerable groups will be critical to develop a better grasp of differentiated adverse human rights impacts as well as the root causes of such impacts on different rightsholders.

\section{New Thematic Directions}

\section{A. Sustainable Development Goals}

The Sustainable Development Goals (SDGs) and Agenda 2030 is an obvious subject for future BHRJ scholarship. The 17 global goals embed human rights at their core. They range from ending discrimination to addressing issues concerning health and inequality. Business has been invited to the table to contribute to sustainable development, in particular, by virtue of SDG 17, which calls on states to 'enhance the global partnership for sustainable development, complemented by multi-stakeholder partnerships that mobilize and share knowledge, expertise, technology and financial resources, to support the achievement of the sustainable development goals in all countries, in particular developing countries'. ${ }^{13}$

\footnotetext{
12 See, e.g., Human Rights Council, 'Gender Dimensions of the Guiding Principles on Business and Human Rights', A/HRC/41/43 (23 May 2019).

13 United Nations, 'Sustainable Development Goals and Agenda 2030', https://www.un.org/sustainabledevelopment/ development-agenda/ (accessed 28 January 2019).
} 
This call to action is an open invitation to the private sector to partner with governments in achieving the SDGs. In addition, business itself tends to see the SDGs beneficial in terms of its own agenda. International bodies such as the Global Reporting Initiative, the UN Global Compact and the World Business Council for Sustainable Development (WBCSD) have developed tools to encourage business to contribute to global goals in a way that simultaneously enhances their own bottom line. The Business Commission on Sustainable Development projects that the business opportunities in creating a sustainable world for 9 billion people could be worth US\$3-10 trillion a year by $2050 .{ }^{14}$

Some institutions such as the Danish Institute for Human Rights, a national human rights institution, and organizations such as Shift and Oxfam, have started to examine the ways in which businesses are using the UNGPs to contribute to the 2030 Agenda. They argue that perhaps the most significant contribution that businesses could make to achieving the SDGs is to eliminate their adverse impacts and abuses. ${ }^{15}$ Others have raised concerns that the BHR agenda could be undermined by the SDGs, since the latter invite companies to cherry-pick and may divert the focus from the prevention of harm to selective projects with positive impact. ${ }^{16}$ However, despite much attention being given to the SDGs in policy and practice, there has been a dearth of research and scholarly discourse focused on what role-both positive and negative-business can and should play, and what impact it will have on human rights via the 2030 Agenda. The intersection between the SDGs and the UNGPs in particular remains largely unexplored from a scholarly perspective to date. We would like to invite scholars to use $B H R J$ as a platform to address this deficit.

\section{B. Finance}

Global finance and capital are levers for advancing corporate respect for human rights. Banks, investors and states provide capital and are the gatekeepers who decide how capital is deployed. The larger question of how financial actors can use their leverage to influence businesses to respect human rights is another question that remains largely uncharted. In BHRJ, we have considered some aspects of finance such as the connection between impact investing and $\mathrm{BHR},{ }^{17}$ or new approaches by banks to detect modern slavery, ${ }^{18}$ and the relationship between tax avoidance and human rights. ${ }^{19}$ However, there are many unexplored issues arising from the connection between finance and human rights.

\footnotetext{
14 Business Commission on Sustainable Development, 'Better Business, Better World' (2017), http:// report.businesscommission.org/report (accessed 7 June 2019).

15 Caroline Rees, 'What Do the UN Sustainable Development Goals Have to Do with Corporate Respect for Human Rights?', Shift (September 2016), https://www.shiftproject.org/resources/viewpoints/sustainable-development-goalscorporate-respect-human-rights/ (accessed 28 January 2019).

16 Uwe Gneiting, Cathrine Bloch Veiberg and Amol Mehra, 'Why the Business and Human Rights Community Needs to Engage with the SDGs', Cambridge Core Blog (23 November 2017), http://blog.journals.cambridge.org/2017/11/23/ why-the-business-and-human-rights-community-needs-to-engage-with-the-sdgs/ (accessed 12 June 2019).

17 Stephen K Park, 'Social Bonds for Sustainable Development: A Human Rights Perspective on Impact Investing' (2018) 3:2 Business and Human Rights Journal 233.

18 Maria A Van Dijk, Marijn De Haas and Ruben Zandvliet, 'Banks and Human Trafficking: Rethinking Human Rights Due Diligence' (2018) 3:1 Business and Human Rights Journal 105.

19 Shane Darcy, 'The Elephant in the Room: Corporate Tax Avoidance and Business and Human Rights' (2017) 2:1 Business and Human Rights Journal 1.
} 
Finance governs almost every aspect of our lives and has the power to liberate as well as enslave. With the world's total wealth valued at a staggering US\$318 trillion in 2018being four times larger than the combined output of all the world's economies-there is, apparently, plenty to go around. ${ }^{20}$ Yet, while proponents of finance and free markets point to the trickle-down effect as its contribution to poverty reduction, the World Bank's most recent data showed that 736 million people around the globe still live on less than US\$1.90 a day. ${ }^{21}$

What role can the financial system play in reducing inequality and safeguarding human rights protection in a world of markets, trade and capitalism? We are inspired by David Kinley's answers to such questions. In his recent book, Necessary Evil, he turns the notion of the financial sector as a neutral and amoral actor, and emphasizes the need for the sector to regain the public trust and credibility it has lost over the past decade, through a commitment to human rights. ${ }^{22}$ We hope to see research that furthers Kinley's observations and examines how financial institutions have responsibility, alongside other businesses, for respecting human rights.

There are many other issues arising in the financial sector. The convergence or divergence of norms that focus on the roles and responsibilities of banks and other financial gatekeepers is a critical issue. As Jonathan Kaufman notes, 'it would really help to advance the practical application of this field to get more rigorous research and analysis on the legal underpinnings of financier liability and the theories that could push it beyond its traditional limitations'. At the level of global governance, many emerging standards and guidelines focus on what the responsibility of banks to respect human rights looks like when it comes to their client and business relationships. These different policy initiatives include the OECD Corporate Lending Due Diligence Guidance, which is currently under development, the revision of the Equator Principles (focused on project finance), the Thun Group of Banks guidance on human rights due diligence ${ }^{23}$ and the United Nations Environment Program Finance Initiative Principles for Responsible Banking. There are many normative developments underway that deserve further attention both in terms of their substance and how they are implemented by financial institutions. ${ }^{24}$ The role of both private sector finance as well as public sector finance is also essential-governments, through development finance, commercial lending, and export credit, as examples, also provide large amounts of capital in the name of facilitating trade and commerce.

Investors are yet another important group in the financial system. In his open letter to CEOs in 2018, Larry Fink, the CEO of Blackrock, the largest asset management company

\footnotetext{
20 Credit Suisee, 'Global Wealth Report 2018' (18 October 2018), https://www.credit-suisse.com/corporate/en/ articles/news-and-expertise/global-wealth-report-2018-us-and-china-in-the-lead-201810.html (accessed 15 April 2019).

21 World Bank, Poverty and Shared Prosperity 2018: Piecing Together the Poverty Puzzle (English) (Washington, DC USA: World Bank Group, 2018), http://documents.worldbank.org/curated/en/104451542202552048/Poverty-andShared-Prosperity-2018-Piecing-Together-the-Poverty-Puzzle (accessed 12 June 2019).

22 David Kinley, Necessary Evil: How to Fix Finance by Saving Human Rights (Oxford, UK: Oxford University Press, 2018).

23 Thun Group of Banks, 'Paper on the Implications of UN Guiding Principles 13b and 17 in a Corporate and Investment Banking Context' (December 2017).

24 United Nations Environment Programme - Finance Initiative, 'Principles for Responsible Banking', https:// www.unepfi.org/banking/bankingprinciples/ (accessed 12 June 2019).
} 
in the world, called for CEOs to step up and assume a role abdicated by many governments, in making the world a better place. He calls out governments for abandoning their duty to address major global challenges and reflects that '[a]s a result, society is increasingly turning to the private sector and asking that companies respond to broader societal challenges'. ${ }^{25}$ Fink cites environmental impact, workforce diversity and community engagement as among the larger issues with which companies must grapple, and exhorts them to move beyond delivering short-term profits. His 2019 letter echoed these themes and called upon CEOs again to reimagine the purpose of the corporation. ${ }^{26}$ Despite this clarion call, we have yet to see the power of investors and asset managers much affecting the human rights performance of companies. There is little scholarship examining how and why major investors should care about human rights. ${ }^{27}$ We thus welcome further examination of the role of investors in influencing how companies address human rights risks to rightsholders.

\section{The Political Role of Corporations}

The fact that many corporations, especially large multinationals, yield enormous power and influence is not a new insight. ${ }^{28}$ However, the BHR debate has engaged relatively rarely with it at a conceptual level, despite the intimate connection between the very idea of human rights and the abuse of governmental power. ${ }^{29}$ Nevertheless, recent discussions in the BHR field about political involvement, the use of leverage, and the distortion of public discourse and decision-making have put the topic of corporate power on the agenda, at least implicitly. We would welcome scholarship that fleshes out such discussions.

The recent backlash against human rights and the rise of right-wing populist movements and anti-democratic sentiments around the globe have led to new political demands for corporations to use their power and influence in defence of human rights. As a result, human rights activists increasingly look to corporations to fill the void left by political leadership. Business leaders are expected not only to do what it takes to respect human rights throughout their business operations in all types of environments, but also to proactively engage in defending human rights against the movements actively undermining them. Increasingly, they are called on to resist damaging policies, oppose harmful speech and the repeal of human rights instruments more generally.

\footnotetext{
25 Larry Fink, 'Larry Fink's 2018 Letter to CEOs - A Sense of Purpose', Blackrock (2018), https://www.blackrock.com/ corporate/investor-relations/2018-larry-fink-ceo-letter (accessed 12 June 2019).

26 Larry Fink, 'Larry Fink's 2019 Letter to CEOs - Profit \& Purpose', Blackrock (2019), https://www.blackrock.com/ americas-offshore/2019-larry-fink-ceo-letter (accessed 12 June 2019).

27 Muzaffar Khan, George Serafeim and Aaron Yoon, ‘Corporate Sustainability: First Evidence on Materiality’ (2016) 91:6 The Accounting Review 1697.

28 See Charles Derber, Corporation Nation. How Corporations Are Taking Over Our Lives and What We Can Do About It (New York, USA: St Martin's Griffin, 1998); David C Korten, When Corporations Rule the World (San Francisco, CA, USA: Berrett-Koehler Publishers, 1995).

29 Some notable recent exceptions are John G Ruggie, 'Multinationals as Global Institution: Power, Authority and Relative Autonomy' (2017) 12:3 Regulation and Governance 317; Nien-hê Hsieh, 'Business Responsibilities for Human Rights: A Commentary on Arnold' (2017) 2:2 Business and Human Rights Journal 297; Florian Wettstein, Multinational Corporations and Global Justice: Human Rights Obligations of a Quasi-Governmental Institution (Stanford, CA, USA: Stanford University Press, 2009).
} 
Furthermore, they are increasingly expected to take a stand on social issues, ${ }^{30}$ engage in human rights advocacy ${ }^{31}$ and actively support human rights defenders. ${ }^{32}$ Corporations, in other words, are expected to become 'corporate human rights defenders'themselves. In the Netherlands, for example, two dozen companies issued a public letter in support of the recently passed Child Labour Due Diligence Law. The law mandates due diligence with respect to the use of child labour in supply chains for all businesses operating in the Netherlands. In the now infamous Thammakaset case, the Foreign Trade Association intervened in support of human rights defender Andy Hall and the Migrant Workers Rights Network, in a defamation lawsuit brought against them. ${ }^{33}$ BHR scholarship should systematize and make conceptual sense of such new political roles of corporations in the defence and protection of human rights, not least regarding how such activity relates to the UNGPs.

Treating corporations as political institutions with political responsibilities more generally is not a new idea. Already in 1960, Dow Votaw argued that in order to get a proper grasp of corporate responsibility, we need to understand corporations' social, political and economic nature. ${ }^{34}$ Peter Ulrich argued that corporate responsibility never stops with the narrow business conduct, but always includes a political dimension, that is, a responsibility for the policies and politics governing the market in which they compete ${ }^{35}$-for the structural context in which it operates. ${ }^{36}$ These and other works led to the emergence of a new research paradigm labelled 'political CSR' in the mid-2000s, ${ }^{37}$ whose aim has been to conceptualize the political stature of multinationals and their role in new, polycentric global governance schemes. Further research on positive lobbying or 'lobbying for the good' as well as on 'corporate political advocacy' has explored political responsibility of corporations within and beyond formal political processes and their role in tackling global problems. ${ }^{38}$ We hope that BHR scholars will build on this strand of research.

However, there is a dark side of corporate political power that warrants further scholarly engagement as well. Despite the calls for harnessing corporate power for the advancement and realization of human rights, dangers loom in the distortion of public and political processes through private interests when corporations enter the policy space. The

\footnotetext{
30 Florian Wettstein and Dorothea Baur, “'Why Should We Care About Marriage Equality?": Political Advocacy as a Part of Corporate Responsibility’ (2016) 138:2 Journal of Business Ethics 199.

31 Florian Wettstein, 'The Duty to Protect: Corporate Complicity, Political Responsibility, and Human Rights Advocacy' (2010) 96:1 Journal of Business Ethics 33.

32 Michael Ineichen, 'Protecting Human Rights Defenders: A Critical Step Towards a More Holistic Implementation of the UNGPs' (2017) 3:1 Business and Human Rights Journal 97.

33 Ibid.

34 Dow Votaw, 'The Politics of a Changing Corporate Society' (1961) 3:3 California Management Review 105.

35 Peter Ulrich, Integrative Economic Ethics: Foundations of a Civilized Market Economy (Cambridge, UK: Cambridge University Press, 2008).

36 See our third point on structural issues above.

37 Dirk Matten and Andrew Crane, 'Corporate Citizenship: Toward an Extended Theoretical Conceptualization' (2005) 30:1 Academy of Management Review 166; Andreas G Scherer and Guido Palazzo, 'Toward a Political Conception of Corporate Responsibility: Business and Society Seen From a Habermasian Perspective' (2007) 32:4 Academy of Management Review 1096.

38 Kyle Peterson and Marc Pfitzer, 'Lobbying for Good' (2009) 7:1 Stanford Social Innovation Review 44; Wettstein and Baur, note 30 .
} 
line between proactive political engagement and what has been coined as 'corporate capture' is fluid. Corporate capture denotes the undermining of public space and processes by private corporate interests. Iconic popular works such as Naomi Klein's No Logo (1999), Charles Derber's Corporation Nation (1998) or Noreena Hertz's The Silent Takeover (2001) have pointed to such processes in the 1990s and early 2000s already. ${ }^{39}$ Court rulings granting unprecedented power to corporations (including the ability to claim human rights) and the use of strategic lawsuits against public participation (SLAPP) by corporations, among other things, show that the takeover of public, judicial and policy space by corporations is ongoing today. The difference may be that it is happening not secretly and in silence anymore, but noisily and in plain sight. In regard to such problematic aspects of corporate political activity in the BHR space and the negative impact this may have on the realization of human rights, publication of more systematic research in forums such as $B H R J$ is needed.

\section{Technology and Human Rights}

The impact of technology on human rights is yet another area where we would envision an increase in future submissions to BHRJ. There are many interrelated issues arising from major advancements in technology-from automation of the workplace with robots, the rise of autonomous technology and devices such as cars, drones and weapons, and the use of artificial intelligence (AI) via algorithms for decision making regarding a broad array of topics, including surveillance, credit scoring, medical appointment scheduling, and even criminal sentencing, to name but a few.

In a recent issue of $B H R J$, Vivek Krishnamurthy lamented the prevalent view among technology companies that 'technologies are morally neutral, and that the responsibility for the adverse consequences of any particular use of technology should be borne by the user'. ${ }^{40}$ Perhaps no other technology presents as much peril to human rights as AI. The question of how machines should be designed to respect human rights is one that is commanding substantial attention among scholars and practitioners alike. In late 2018, the European Commission's High-Level Expert Group on Artificial Intelligence published Draft Ethics Guidelines for Trustworthy AI in which they declare that 'trustworthy AI has two components: (1) it should respect fundamental rights, applicable regulation and core principles and values, ensuring an "ethical purpose" and (2) it should be technically robust and reliable since, even with good intentions, a lack of technological mastery can cause unintentional harm'. ${ }^{41}$ We see the continuing development and deployment of $\mathrm{AI}$ as a critical area of focus for future BHR scholarship-from autonomous weapons, to facial recognition and how AI will impact various human rights such as the right to life, the right to privacy and the right to not be subject to discrimination. Ethicists and law and technology scholars are examining these

\footnotetext{
39 Naomi Klein, No Logo: Taking Aim at the Brand Bullies (New York, USA: Picador, 1999); Derber, note 28; Noreena Hertz, The Silent Takeover: Global Capitalism and the Death of Democracy (London, UK: William Heinemann, 2001).

40 Vivek Krishnamurthy, 'Are Internet Protocols the New Human Rights Protocols? Understanding "RFC 8280 Research into Human Rights Protocol Considerations"', forthcoming, Business and Human Rights Journal.

41 European Commission, 'Draft Ethics Guidelines for Trustworthy AI' (18 December 2018), https:// ec.europa.eu/digital-single-market/en/news/draft-ethics-guidelines-trustworthy-ai (accessed 3 February 2019).
} 
issues, but we believe the scholarly discourse would greatly benefit from a specific BHR lens.

China, simultaneously an authoritarian state and a rising global economic power, represents by itself a fertile pasture for future work at the intersection of technology and human rights. Since China began its economic reforms in the late 1970s, BHR attention to China has largely been centred on supply chain issues and the labour rights of workers (including migrant workers) in the factories, which manufacture everything from sneakers and T-shirts to smartphones and televisions for the whole world. In addition to the continuing focus on supply chain and outward investment issues, technology and human rights are likely to gain more traction with BHR scholars focused on China.

One prominent example of such concerns is the uproar from Google employees when they learned that the company was developing a 'Dragonfly' product that would be used to re-enter the Chinese internet search market in a way that would comply with the strict internet censorship practised in China. These BHR concerns about technology are not limited to foreign companies operating in China. Chinese companies are starting to pull ahead in the technology race, especially in the AI field. SenseTime is the most valuable AI company in the world, with a valuation of around US\$5 billion. Its rival Megvii, valued at US\$2 billion, has openly declared that it wants with its facial recognition technology to 'build the eyes and brains' of city police powers 'beyond what is humanly possible'. ${ }^{42}$ These emerging technology-related BHR issues require a re-examination by scholars and practitioners alike of the longstanding BHR questions in the China context, such as the relationship of economic rights to political and civic rights and the extent and limits of business responsibility for human rights in China. ${ }^{43}$

The global rise of social media companies also presents diverse human rights risks. In 2018, prominent business and human rights scholars and teachers, including John Ruggie, sent a letter to Facebook, in the wake of the Cambridge Analytica election scandal, where the personal data of hundreds of thousands of Facebook users was harvested and used to help elect Donald Trump president of the United States in 2016. The letter observed that "we have entered a period in which election disinformation is being weaponized to manipulate the outcomes of democratic elections. That human rights risks are inherent in the misuse of social media to manipulate election results is beyond doubt'. 44

In addition to concerns about the impact of social media on democratic elections and civil discourse, social media companies such as Facebook and Google depend crucially on amassing the personal data, predilections, hobbies and patterns of friendship and associations to sell advertisement space to marketers of commercial products and political campaigns. The human rights implications of such data collection are

\footnotetext{
42 Eamon Barrett, 'In China, Facial Recognition Tech is Watching You', Fortune (28 October 2018), http:// fortune.com/2018/10/28/in-china-facial-recognition-tech-is-watching-you/ (accessed 3 February 2019).

43 Michael A Santoro, China 2020: How Western Business Can - and Should - Influence Social and Political Change in the Coming Decade (Ithaca, NY, USA: Cornell University Press, 2009).

44 Global Business and Human Rights Scholars Association, 'Letter to Elliott Schrage and David Ginsberg' (17 May 2018), https://bhrscholarsassociation.org/wp-content/uploads/2019/01/Facebook-Letter-PDF.pdf (accessed 12 June 2019).
} 
manifest, ${ }^{45}$ but not yet fully understood. In coming years, we would welcome articles that address the intersection between social media technology and human rights from both empirical as well as conceptual and normative perspectives.

\title{
IV. CONCLUSION
}

As we take a long view of the 'new era' of the BHR field, we look forward to receiving submissions that extend the reach and depth of the field. Our goal is to expand the menu and to encourage others to think broadly about where their own research will go. We are also conscious of the fact that, in singling out these areas of future scholarship, we have not included many other timely issues that deserve scholarly analysis as well. Our first special issue on security and human rights was testimony to our openness to venture into other unchartered territories.

We are grateful to our editors, advisers, contributors and readership for giving us the privilege to publish excellent, novel and innovative BHR scholarship during the past three years and in turn make a contribution to building, developing and shaping the BHR field. We hope to continue working with all of you and with a new generation of scholars to produce cutting edge academic work that can ultimately have a positive impact on the human rights of individuals throughout the world who are affected by the activities of business.

\author{
Surya DEVA \\ Anita RAMASASTRY \\ Florian WETTSTEIN \\ Michael SANTORO
}

Editors-in-Chief

\footnotetext{
45 UN Human Rights Committee, 'General Comment No. 16: Article 17 (Right to Privacy): The Right to Respect of Privacy, Family, Home and Correspondence, and Protection of Honour and Reputation' (8 April 1988), http:// www.refworld.org/docid/453883f922.html (accessed 3 February 2019).
} 